\title{
Entendendo as Atitudes da Terceira Idade das Classes A e B de São Paulo em Relação ao Turismo
}

\section{Understanding Senior Citizens Attitudes from A and B Classes of São Paulo Related to Tourism}

\author{
Maria de Lourdes Bacha ${ }^{1}$ \\ Nadia Wacila Hanania Vianna ${ }^{2}$
}

\begin{abstract}
Resumo
O segmento terceira idade das classes A e B vem se tornando um mercado atrativo principalmente por suas taxas de crescimento. O principal objetivo deste paper é entender as atitudes em relação ao turismo por indivíduos da terceira idade, residentes em São Paulo, através da identificação de suas características do consumo de turismo como lazer. O trabalho principia com uma apresentação do tema e sua relevância e, na seqüência o referencial teórico aborda o tema turismo. A metodologia empregada foi quantitativa e os dados foram obtidos através de uma survey, aplicada a uma amostra não probabilística de 700 indivíduos da terceira idade das classes A e B, selecionados através do critério Brasil, residentes no município de São Paulo, em julho de 2005.
\end{abstract}

Palavras-chave: turismo; terceira idade; atitudes.

\begin{abstract}
The main objective of this paper is to understand the attitudes of people over 60 towards tourism as leisure through the identification of their characteristics of consumption. The work begins with the presentation of the theme relevance and then focuses on the revision of the literature on tourism. The chosen methodology was quantitative with the realization of a survey conducted in July 2005 using a non probabilistic sample of 700 people over 60 from upper social class inhabitants of Sao Paulo city.
\end{abstract}

Keywords: tourism; old age; attitudes.

\section{Introdução}

O objetivo deste paper é entender as atitudes em relação ao turismo por indivíduos da terceira idade, residentes na cidade de São Paulo, através da identificação de características do consumo de turismo como lazer, como forma de subsidiar a compreensão de sua influência sobre o comportamento de compra, bem como comparar eventuais diferenças entre

\footnotetext{
${ }^{1}$ Graduada em Administração pela FEA-USP. Pós-doutorado em Comunicação e Semiótica pela PUC-SP. Docente do Centro de Ciências Sociais Aplicadas da Universidade Presbiteriana Mackenzie. E-mail: mlbacha@superig.com.br.

${ }^{2}$ Graduada em Matemática. Doutora em Administração pela FEA-USP. Docente da Universidade Ibirapuera. E-mail: nhvianna@terra.com.br.
} 
tipos de consumidores idosos. Parte-se da hipótese de que a atitude seria predisposição para agir, que uma vez conhecida, permitiria analisar a oferta de produtos e serviços, bem como os esforços de marketing, no sentido de melhor atender às necessidades específicas dessa faixa etária e classes sociais no que se refere ao turismo.

O estudo se justifica principalmente porque o Brasil acaba de entrar no grupo dos dez países com maior percentual de idosos. Compõem esse grupo: China, Índia, Estados Unidos, Japão, Rússia, Alemanha, Itália, França, Brasil e Espanha. De acordo com o IBGE (2006), são 17,6 milhões de brasileiros na faixa etária acima de 60 anos (9,7\% da população), correspondendo, atualmente, a $2 \%$ dos idosos do mundo.

Além disso, há necessidade de se considerar a relevância do turismo como atividade econômica. Dados do Banco Central e do Boletim de Desempenho Econômico do Turismo (Fundação Getulio Vargas, em parceria com o Ministério do Turismo) revelam que 2005 foi o melhor ano do turismo internacional no Brasil em todos os segmentos pesquisados: Meios de Hospedagem, Operadoras de Turismo, Agências de Viagens, Turismo Receptivo, Eventos, Restaurantes, Transporte Aéreo e Parques Temáticos.

Os dados do Banco Central mostram que a receita gerada para o Brasil, em 2005, foi de US\$ 3,861 bilhões, o que representou o significativo crescimento de 19,83\% em relação a 2004 . De acordo com a Empresa Brasileira de Turismo (EMBRATUR, 2006), o número estimado de turistas estrangeiros em 2005 foi de 5,5 milhões, aproximadamente 14\% a mais do que em 2004, com aumento da participação relativa dos turistas europeus.

Segundo a ABAV (Associação Brasileira das Agências de Viagem, 2005), 20 \% da receita deste setor provêm do público da terceira idade, sendo o turista pertencente à faixa etária superior a 55 anos, proveniente da Europa e América do Norte (responsável por cerca de 60\% dos gastos mundiais em turismo internacional, segundo a Organização Mundial Do Turismo OMT, 1999).

\section{Turismo}

Schrriner (2004) explica que o turismo nasceu e se desenvolveu com o capitalismo, mas foi a partir da década de 60 que ganhou peso econômico, podendo ser entendido como indústria, por se tratar de um setor com diversas atividades heterogêneas, atuando em conjunto para possibilitar e viabilizar uma viagem. 
Para Vaz (1999) um mercado turístico é resultado de transações que se estabelecem entre agentes econômicos para atender a uma demanda. Haveria assim três agentes envolvidos nesse processo de troca: operadoras, prestadores de serviços da localidade e turistas. Nesse contexto, o autor define essa relação como indústria do turismo, na medida em que se desenvolve uma demanda constante para um dado destino e um produto passa a ser comercializado para atendê-la.

Acerenza (2002) considera três elementos que constituem a base da movimentação do sistema turístico: o turista, o destino emissor (de onde sai o viajante) e o destino receptor (para onde ele vai). Nesse sistema, o turista atua como ativador, quando decide viajar do local fixo de sua residência para um outro local destino, e, os prestadores de serviços possibilitam viabilizar tal dinâmica; incluem-se dentre esses últimos, os serviços de transporte, de alimentação, de hospedagem e de agências de viagens.

Para a Empresa Brasileira de Turismo (EMBRATUR, 2003) o turismo pode ser definido como uma indústria processadora de recursos naturais, culturais, e humanos sem desgastá-los, de maneira articulada e planejada, com a missão de atender os desejos do turista e principalmente promover o desenvolvimento sustentável local.

Por sua vez, Schrriner (2004) argumenta que a definição mundialmente aceita (inclusive pela OMT) considera o turismo como o rol de atividades que as pessoas realizam durante suas viagens e estadias em locais distintos do seu habitual, por um período inferior a um ano, com a finalidade de empreender atividades de lazer ou negócios ou ainda outros motivos.

Segundo a OMT, para que exista turismo é preciso que o indivíduo realize pelo menos um pernoite fora de casa contrariamente à atividade que envolve menos de 24 horas, que é denominada de recreação.

O exame da literatura da área de turismo revela que nos últimos anos houve aumento do interesse de estudos acadêmicos com relação ao tema, destacando-se as teses e dissertações de Acevedo (1998), Souza (1998), Garcia (2001), Beni (1997), Felice (2002), Campos (2003), Casimiro Filho (2003), Amaral (2004), Wanderley (2004), Santos (2005), Silva (2005).

A revisão feita em artigos do ENANPAD/ EMA revelou a seguinte distribuição com relação a temas referentes a turismo: 
Quadro 1 - Resumo da revisão feita em artigos do ENANPAD sobre turismo

\begin{tabular}{|c|c|}
\hline Tema & Artigos \\
\hline $\begin{array}{l}\text { Desenvolvimento Local e } \\
\text { Regional }\end{array}$ & $\begin{array}{l}\text { Zouain; Barbosa; Martellote (2005); Souza; Ferreira; } \\
\text { Souza (2005); Cunha; Cunha (2005); Nonohay; Vieira; } \\
\text { Boaro (2005); Oliveira; Romaniello (2005); Berton; } \\
\text { Cunha; Cunha (2005); Souza; Ferreira; Souza (2005); } \\
\text { Rezende; Rezende (2005); Mazaro; Varzin (2005); } \\
\text { Cunha; Cunha (2005); Silva; Costenaro (2004); } \\
\text { Barbosa; Zamot (2004); Köhler; Durand (2003). }\end{array}$ \\
\hline $\begin{array}{l}\text { Empreendedorismo, Gestão, e } \\
\text { Competitividade }\end{array}$ & $\begin{array}{l}\text { Oliveira; Campomar (2006); Crispim; Dultra (2005); } \\
\text { Barros; Moreira (2005); Ferreira; Chauvel (2004); } \\
\text { Rocha (2004); Toledo; Polero; Valdés (2002); Teixeira } \\
\text { (2001); Dias (2000) }\end{array}$ \\
\hline $\begin{array}{l}\text { Políticas Pública Para o } \\
\text { Desenvolvimento do Turismo, } \\
\text { Marca País }\end{array}$ & $\begin{array}{l}\text { Crescitelli. (2006); Giraldi; Barbosa; O’Neil, Marins } \\
\text { (2005); Oliveira; Romaniello (2005); Barbosa; Zamot } \\
\text { (2004); Pereira (2004). }\end{array}$ \\
\hline Comportamento do Consumidor & $\begin{array}{l}\text { Bacha, Strehlau, Perez (2006); Rezende; Rezende } \\
\text { (2005), Rodrigues (2004); Burlamaqui; Santos (2004); } \\
\text { Ladeira; Guedes; Bruni (2003); Falk; Rebouças (2003). }\end{array}$ \\
\hline
\end{tabular}

Boullón (2004) apresenta uma lista com oito motivações básicas para o turismo, ligadas a cultura, saúde, desejo de mudanças, compras, hedonismo, descanso, prática de esportes ou simplesmente conhecimento.

Qureshi e Walker (apud STUART-HAMILTON, 2002) descobriram que as pessoas mais velhas da classe social "mais alta" visitam mais outros membros de sua família em relação àqueles de outras classes, todavia, as medidas do nível de proximidade emocional entre os membros da família foram aproximadamente iguais em todas as classes sociais.

Cohen (2002) apresenta uma análise crítica das motivações dos turistas em três momentos históricos, observando que ao longo da história as pessoas tendem a minimizar o desconforto e o perigo em suas viagens, considerando que atualmente são encontradas mais opções em seu processo de decisão do que em outros tempos. Em outro estudo, McCannell (2002) tenta explicar o comportamento e motivações de alguns turistas através de uma abordagem psicanalítica.

Na revisão da literatura internacional apareceram as seguintes motivações: prazer de viajar, descanso, relaxamento, nostalgia, experiências culturais, “sightseeing” e encontrar pessoas (JAVALGI; THOMAS; RAO, 1992; MULLER; O'CASS, 2001; GEE; MAKENS; CHOY, 
1989). Com relação às barreiras para viagem, a literatura internacional aponta vários fatores, que incluem falta de saúde, de equipamento, informação tempo e dinheiro, medo de serem desaprovados, falta de energia e limitações físicas (KIM; KIM, 1996; MCGUIRE, 1984; MCGUIRE; BOYD; TEDRICK, 1996; ZIMMER; BRAYLEY; SEARLE, 1995; HUANG, 2003).

Campos (2003) observa que, de modo geral, as discussões em torno do turismo para terceira idade são focadas, principalmente, em termos do que este pode gerar de benefícios e vantagens para o mercado turístico: ocupação de equipamentos turísticos na baixa estação; expansão e melhoria da rede hoteleira; incentivo à diminuição de preços junto às empresas de turismo; qualificação de mão-de-obra local; valorização do patrimônio cultural e melhoria da infra-estrutura da comunidade receptora.

Cleaver (apud CAMPOS, 2003) afirma que os turistas idosos têm sido tema de pesquisas empíricas ligadas à motivação, comportamento em viagem, segmentação em países como Canadá, Alemanha e Estados Unidos, porém em outros, até muito recentemente, esses não alcançavam uma relevância considerável em termos de estudos e pesquisas.

Fleischer e Seiler (2002) comentam que o turista maduro tende a ser considerado como parte de um grupo homogêneo e, embora haja uma tendência em se generalizar o comportamento do idoso, é preciso observar que existe grande diversidade entre eles, tanto em termos de atitudes como comportamento.

Lee e Tideswell (2005) consideram que em função da motivação dos idosos para as viagens, as empresas deveriam enfatizar viagens curtas e de fins de semana para atender a este segmento, principalmente porque os idosos geralmente se queixam que as viagens cansam.

No Brasil, Ladeira, Guedes e Bruni (2003) conduziram pesquisa em Salvador, relacionadas à terceira idade, revelando que as principais motivações para a viagem seriam "sentir-se vivo" (52\%) e “aproveitar a vida” (38\%).

Acevedo (1998) discute os motivos mais importantes para as pessoas mais idosas viajarem: encontrar pessoas e se socializar (61\%), escapar da rotina do dia-a-dia (82\%), descansar e relaxar (83\%), visitar museus e lugares históricos (66\%), experimentar coisas novas/visitar lugares novos (89\%). No comparativo que a autora fez com outras faixas etárias seriam mais importantes para as pessoas mais idosas: procurar enriquecimento intelectual e espiritual; contar aos amigos sobre a viagem; ir a festivais ou eventos especiais e visitar museus ou 
lugares históricos. A autora também verificou que as pessoas mais velhas demonstram atitude negativa muito mais forte em relação a engajar-se em atividades físicas.

Garcia (2001) discute os motivos declarados por entrevistados da terceira idade, que os impedem de viajar: $86 \%$ apontaram o alto custo das viagens; 25\% declararam que é a falta de companhia, 7\% alegaram motivos relacionados a problemas de saúde pessoal e 8\% problemas familiares.

Segundo Iwasso (2006), intercâmbio também seduz a terceira idade, pois embora com mais de 60 anos, alguns trocam os pacotes turísticos com hotel, guia e city tour pelos alojamentos de universidades e as hospedagens em casas de família e estão descobrindo que intercâmbio não tem limite de idade.

\section{Atitude}

Segundo Rodrigues (2004), as atitudes envolvem o que as pessoas pensam, sentem, e como elas gostariam de se comportar em relação a um objeto, enquanto o comportamento não é apenas determinado pelo que as pessoas gostariam, mas, também, pelo que elas pensam que devem fazer (de acordo com as normas sociais); pelo que elas, geralmente, têm feito (hábito); e pelas conseqüências esperadas de seu comportamento.

Serralvo (2006) explica que as respostas das pessoas sobre o que pensam ou sentem a respeito de um objeto, pessoa ou atividade, expressam sua atitude, ou seja, geralmente gostam ou desgostam de alguma coisa, sem discutir as razões que as levam a esse sentimento. As atitudes do consumidor têm sido investigadas cuidadosamente, mas apesar da grande complexidade que envolve o tema, os progressos nesse campo vêm evidenciando discrepâncias demonstradas pelos consumidores entre suas opiniões e suas atitudes. A atitude, via de regra, implica valorização (aceitação ou rejeição) do objeto ao qual se dirige (SERRALVO, 2006).

Segundo Mattar (1996), a atitude representa uma predisposição para uma reação comportamental em relação a um produto, organização, pessoa, fato ou situação; é persistente no tempo; tende a produzir comportamentos consistentes; pode ser expressa de forma direcional; possui três principais componentes em relação a produtos, organizações, pessoas, fatos ou situações: componente cognitivo - as crenças das pessoas; componente afetivo sentimento das pessoas; e um componente comportamental - predisposição para uma reação comportamental. Sua medição requer processos diferenciados e especiais, com uso de 
diferentes tipos de escalas e inúmeras técnicas que transformam uma série de fatos qualitativos em fatos quantitativos ou variáveis, aos quais se podem aplicar processos de mensuração e de análise estatística.

Revisando bases de artigos, como Proquest, Ebsco, Jstor, foram encontrados 10 trabalhos que tratam especificamente da mensuração de atitudes em relação a turismo (IBRAHIM; GILL, 2005; YUAN et al, 2005; PETTERSSON, 2002; FORMICA, 2002; PEARCE, 2001; CALLAN; KYNDT, 2001; GNOTH; ANWAR, 2000; LUK, 1997; MAZANEC, 1993; ROSS, 1992).

\section{Metodologia e Análise dos Resultados da Pesquisa}

O método utilizado na pesquisa foi quantitativo, do tipo survey, conduzido junto a uma amostra de natureza não probabilística, constituída por 700 indivíduos da terceira idade das classes $\mathrm{AB}$, residentes na cidade de São Paulo. Utilizou-se questionário estruturado aplicado pessoalmente. Os dados obtidos foram analisados a partir de várias técnicas estatísticas. Embora as considerações estatísticas não permitam a elaboração de inferências sobre a população a partir de amostras não-probabilísticas, optou-se por esse tipo de amostra, em função de custos e acessibilidade.

\subsection{Caracterização da amostra estudada}

A amostra apresentou o seguinte perfil:

- $\quad 63 \%$ de entrevistados eram do sexo masculino e $37 \%$ do sexo feminino;

- Segundo a idade, 45\% pertenciam à faixa etária 60-65 anos, 35\% à faixa 66-70 anos, 14\% à faixa 71-76 anos e 6\% tinham mais de 76 anos;

- Quanto ao gasto com lazer, a distribuição foi a seguinte: até R\$100,00 (13\%), entre $\mathrm{R} \$ 101,00$ e $\mathrm{R} \$ 300,00$ (48\%), Entre $\mathrm{R} \$ 301,00$ e $\mathrm{R} \$ 500,00$ (24\%), entre $\mathrm{R} \$ 501,00$ e $\mathrm{R} \$ 1.000,00$ (13\%) e entre $\mathrm{R} \$ 1.001,00$ e $\mathrm{R} \$ 1.500,00$ (1\%);

- Do ponto de vista da renda, a amostra revelou que 4\% dos entrevistados ganhavam até 1 salário mínimo, 60\% ganhavam mais de 1 a 5 salários mínimos, 35 \% ganhavam mais de 5 a 10 salários mínimos e 1\% recebiam acima de 10 salários mínimos;

- Quanto ao estado civil, 73\% eram casados, 2\% eram solteiros, $18 \%$ eram viúvos e 7\% eram separados/divorciados; 
- $95 \%$ declararam ter filhos;

- $\quad 85 \%$ declararam economizar para momentos de necessidade; $7 \%$ revelaram não ter o hábito de economizar, 5\% informaram economizar para viabilizar a compra de bens e apenas $1 \%$ disseram que economizavam para eventuais gastos com turismo.

- Indagados quanto à freqüência de viagens (no contexto de atividades de lazer) $14 \%$ dos entrevistados declararam viajar pelo menos uma vez por mês, enquanto 86\% informaram que viajam raramente ou nunca. Trata-se, portanto, de uma amostra de indivíduos que não têm hábito de fazer viagens freqüentes.

\subsection{Motivação para viagem}

A análise da tabela abaixo revela que os principais motivos para viagem, declarados pela amostra entrevistada são: $87 \%$ rever parentes ou amigos e $83 \%$ diversão. Num patamar inferior, com respostas entre 30 e 50, aparecem: conhecer pessoas (47\%), fazer amigos (46\%) e experimentar coisas novas ou visitar lugares novos (31\%), ir a festivais ou eventos especiais (12\%). Com percentuais iguais ou inferiores a 5\%, aparecem: trabalhar, negócios, procurar enriquecimento espiritual, engajar-se em atividades físicas, visitar museus e lugares históricos, saúde/tratamento médico, procurar enriquecimento intelectual. É interessante observar que rever parentes, conhecer pessoas e fazer amigos são itens que apresentam percentuais bastante significativos, apontando para uma característica de sociabilidade e comunicabilidade da amostra pesquisada.

Tabela 1- Principal motivação para viagem

\begin{tabular}{lc}
\hline Principal motivação para viagem & $\mathbf{\%}$ \\
\hline Rever parentes/ amigos & 87 \\
Diversão & 83 \\
Conhecer pessoas & 47 \\
Fazer amigos & 46 \\
Experimentar coisas novas/visitar lugares & 31 \\
Ir a festivais ou eventos especiais & 12 \\
\hline
\end{tabular}

Os resultados obtidos vão ao encontro daqueles obtidos por autores citados na fundamentação teórica (JAVALGI; THOMAS; RAO, 1992; MULLER; O'CASS, 2001; GEE; MAKENS; CHOY, 1989). 


\subsection{Destino preferido}

As entrevistas revelaram que $71 \%$ dos entrevistados preferem campo, enquanto $16 \%$ escolhem a praia. A análise da tabela abaixo mostra a freqüência relativa de respostas quanto ao destino preferido.

Tabela 2 - Destino preferido

\begin{tabular}{lc}
\hline Destino preferido & \% \\
\hline Campo & 71 \\
Praia & 16 \\
Grandes Centros & 4 \\
Outros & 9 \\
\hline
\end{tabular}

Os dados obtidos diferem daqueles encontrados por Garcia (2001), que apontaram praia, campo, estação de águas e exterior (com freqüência pouco acima de 40\%). As mulheres tendem a preferir praia em percentual maior que os homens, assim como os entrevistados mais novos e de menor escolaridade. Em outro contexto, como a preferência declarada é pelo campo, é este o destino que recebe o maior número de viagens. Como era de se esperar, as viagens ao exterior são privilegiadas pela classe mais alta.

\section{4. Época do ano preferida para viagens}

Na opinião de $91 \%$ dos entrevistados, a época preferida para viagens é o verão; $52 \%$ preferem a primavera, $27 \%$ o outono e $23 \%$ o inverno, conforme abaixo:

Tabela 3 - Época do ano preferida para viagens

\begin{tabular}{lc}
\hline Época do Ano & \% \\
\hline Verão & 91 \\
Primavera & 52 \\
Outono & 27 \\
Inverno & 23 \\
\hline
\end{tabular}

Em relação à época do ano para efetuar viagens as classes mais baixas do estrato social estudado (B1 e B2) apresentam um percentual mais alto do que as demais quanto à preferência pela realização de viagens no verão. Do ponto de vista de faixa etária, o verão é preferido pelas faixas etárias mais jovens, enquanto a primavera é a estação preferida para viagens por aqueles na faixa entre 66 a 71 anos. Os casados tendem a preferir o verão, principalmente quando vão ao campo. Esses dados estão em desacordo com o estudo de Acevedo (1998), segundo o qual a época preferida para viagens da terceira idade seria a baixa estação. A autora em sua revisão bibliográfica conclui que as viagens dos idosos distribuem- 
se pelos meses de baixa temporada, como também aqueles que não coincidem com as férias escolares.

\subsection{Companhia em viagens}

As entrevistas revelaram que 15\% viajam sozinhos. Dos que declaram viajar acompanhados, $68 \%$ se dizem acompanhados pelo cônjuge, 68\% pelos filhos, 35 \% por amigos, 34\% por netos, $24 \%$ por grupos de terceira idade e $12 \%$ por outros parentes.

Tabela 4 - Companhia em viagens

\begin{tabular}{lc}
\hline Tipo de companhia & $\mathbf{( \% )}$ \\
\hline Cônjuge & 68 \\
Filhos & 68 \\
Amigos & 35 \\
Netos & 34 \\
Grupos de $3^{\text {a }}$ Idade & 24 \\
Nenhuma & 15 \\
Outros parentes & 12 \\
\hline
\end{tabular}

Garcia (2001) encontrou resultados diferentes: 41\% dos entrevistados de sua pesquisa informaram viajar com grupos de excursão, 30\% sós, $19 \%$ com amigos, $28 \%$ com parentes e 26\% com marido ou companheiro.

Segundo Acevedo (1998), a companhia na viagem não parece ter apresentado muito interesse para pesquisas, embora, de maneira geral, se possa dizer que o idoso tende a viajar acompanhado de algum membro da família, principalmente o cônjuge.

\subsection{Número e duração das viagens de lazer}

Com relação ao número de viagens $68 \%$ realizaram até 5 viagens nos três últimos anos enquanto 30\% realizaram de 6 a 10 viagens. O percentual de indivíduos que viajaram mais de 11 vezes é igual a 2\%. A média ponderada para esta amostra é inferior a 6.

Tabela 5 - Número das viagens de lazer

\begin{tabular}{lc}
\hline Número de viagens & Freqüência (\%) \\
\hline Até 5 & 68 \\
De 6 a 10 & 30 \\
De 11 a 15 & 1 \\
Mais de 15 & 1 \\
\hline
\end{tabular}

Do ponto de vista de sexo não se verificou diferenças significativas no número de viagens. A média de viagens para homens é 4.46 e para as mulheres 4,38. Quando analisado segundo a 
faixa etária, os mais idosos informaram ter viajado um maior número de vezes, conforme se depreende dos cálculos de número médio de viagens por faixa: de 60 a 65 a média de viagens foi 4,04 de 66 a 70, a média encontrada foi 4,45, de 71 a 75, a média foi 5,24 e para aqueles com mais de 76, a média foi 5,13. Se considerada a classe social, nota-se significativa diferença na quantidade de viagens, pois a média obtida para classe A foi 6,43, enquanto que para as classes B1 e B2 foi igual a 4,71 e 3,70, respectivamente.

A análise dos dados mostra ainda, que os indivíduos com maior número de filhos, relatam ter feito um menor número de viagens. Tomando-se por base para a análise, a atitude com relação à poupança, foi possível notar que o número de viagens foi maior para aqueles habituados a economizar, seja para saúde ou para turismo; aqueles que não costumam economizar (82\%) fizeram menos de 5 viagens no período considerado. A tabela a seguir sintetiza as informações obtidas através da amostra, com relação à duração média das viagens:

Tabela 6 - Duração média das viagens

\begin{tabular}{lc}
\hline Duração média das viagens (dias) & Freqüência \% \\
\hline Até 3 & 23 \\
De 4 a 6 & 59 \\
De 7 a 14 & 12 \\
De 15 a 30 & 5 \\
Mais de 30 & 1 \\
\hline
\end{tabular}

Convém notar, que a maior parte (60\%) dos indivíduos pesquisados informou ter feito viagens com duração de 4 a 6 dias. As viagens mais longas foram realizadas por 20\% da amostra. Considerando o destino preferido, 38\% das viagens para o campo duraram até 3 dias e 36\% tiveram duração de 4 a 6 dias. As viagens mais curtas foram feitas à praia, tendo $40 \%$ delas durado até 3 dias e $54 \%$ de 4 a 6 dias. Com relação às viagens para o exterior, $40 \%$ foram efetuadas em 7 a 14 dias e 40\% levaram mais de 15 dias. Do ponto de vista do estado civil, os viúvos apresentaram percentuais superiores de viagens mais longas e, como seria de se esperar, em se tratando do exterior como destino, as viagens referidas pela amostra tiveram a maior duração (acima de 15 dias).

\subsection{Turismo e estado de espírito da terceira idade}

A forma como os entrevistados vinham se sentindo nos últimos tempos foi avaliada segundo uma escala adaptada de Burns, Lawlor e Craig (2004), incluindo 27 frases, para as quais se pedia para que os entrevistados escolhessem aquelas que melhor representassem seus sentimentos. Com base nas assertivas indicadas, foram criadas categorias "ups" e "downs", 
separando os entrevistados em dois grupos, com diferenças acentuadas no estado de espírito, para os quais foram feitos cruzamentos:

- “ups” (de bem com a vida): 93\% estão basicamente satisfeitos com sua vida; 85\% acham que é maravilhoso estar vivo; 82\% gostam de levantar de manhã; 72\% acham fácil tomar decisões; $70 \%$ consideram que sua mente continua tão clara quanto antes; $68 \%$ se sentem cheios de energia; 66\% ficam felizes na maior parte do tempo; 61\% ficam bem-humorados na maior parte do tempo; 55\% acham a vida excitante.

- “downs” (insatisfeitos e deprimidos): 44\% têm ficado chateados com alguns pensamentos; 35\% têm medo que alguma coisa ruim lhes aconteça; 27\% preocupam-se com o passado; 23\% acham difícil começar novos projetos; 23\% freqüentemente se preocupam com o futuro; 22\% preferem ficar em casa ao invés de sair; 17\% ficam agitados freqüentemente; $10 \%$ têm dificuldade em se concentrar; 9\% preferem evitar encontros sociais; $7 \%$ se sentem deprimidos; $7 \%$ sentem que a vida está vazia; $6 \%$ têm vontade de chorar freqüentemente; $6 \%$ abandonaram algumas de suas atividades; $5 \%$ freqüentemente ficam chateados; $4 \%$ sentem que têm mais problemas com sua mente; $2 \%$ sentem que a situação não tem solução; $2 \%$ se sentem desvalorizados; $1 \%$ acreditam que os outros estão em melhor situação.

A análise dos dados mostrou que o grupo “down” viajou significativamente mais que o total da amostra (76\% contra 68\%), embora considerando a duração, suas viagens são mais curtas do que as do grupo "up”. Pode-se dizer que os dados apresentam uma perspectiva interessante e relevante do ponto de vista de indivíduos da terceira idade e sua percepção de si mesmos e também do grupo etário do qual fazem parte, o que foge da abordagem habitual, que considera o idoso como uma pessoa-problema, isto é, sempre insatisfeita e deprimida.

\subsection{Atitudes com relação a turismo}

Foram avaliadas algumas atitudes com relação a turismo, segundo frases submetidas aos entrevistados sob a forma de escala de concordância. O constructo foi elaborado a partir de uma escala Likert adaptada de Stuart-Hamilton (2002) e Burns, Lawlor e Craig (2004), construída segundo Netemeyer, Bearden e Sharma (2003) e também DeVellis (2003). Os questionários foram tratados com o software estatístico SPSS (v 13.0). Os resultados da análise fatorial mostraram KMO de 87\%, confirmando a adequabilidade da amostra. As frases referentes a atitudes com relação a turismo foram agrupadas em cinco componentes. 


\begin{tabular}{|c|c|c|c|c|c|}
\hline Assertivas & 1 & 2 & 3 & 4 & 5 \\
\hline $\begin{array}{l}\text { Turistas na terceira idade necessitam de viagens } \\
\text { organizadas com roteiros pré-estabelecidos }\end{array}$ & ,927 & & & & \\
\hline $\begin{array}{l}\text { Turistas na terceira idade necessitam de viagens } \\
\text { organizadas com acompanhamento de guias }\end{array}$ & 924 & & & & \\
\hline $\begin{array}{l}\text { Turistas na terceira idade escolhem livremente } \\
\text { os períodos de viagem }\end{array}$ & 910 & & & & \\
\hline $\begin{array}{l}\text { Turistas na terceira idade precisam viajar com } \\
\text { grupos homogêneos }\end{array}$ & 904 & & & & \\
\hline $\begin{array}{l}\text { Turistas na terceira idade necessitam de } \\
\text { acompanhamento da família }\end{array}$ & ,892 & & & & \\
\hline $\begin{array}{l}\text { Turistas na terceira idade necessitam de locais } \\
\text { com boas condições físicas (ex: escada rolante) }\end{array}$ & ,881 & & & & \\
\hline $\begin{array}{l}\text { Turistas na terceira idade não têm compromissos } \\
\text { de trabalho }\end{array}$ & ,876 & & & & \\
\hline $\begin{array}{l}\text { Turistas na terceira idade precisam de cuidados } \\
\text { especiais com alimentação }\end{array}$ & ,550 & & & & \\
\hline Nunca como comida feita por pessoas estranhas & & ,697 & & & \\
\hline Tenho muito medo de ficar doente em viagens & & 694 & & & \\
\hline Tenho medo de acidentes em viagens & & ,607 & & & \\
\hline Nunca visito lugares onde não conheço ninguém. & & & ,626 & & \\
\hline $\begin{array}{l}\text { Sinto-me inseguro em lugares onde não conheço } \\
\text { ninguém }\end{array}$ & & & ,605 & & \\
\hline $\begin{array}{l}\text { Acho que vale a pena correr riscos para viver } \\
\text { situações novas }\end{array}$ & & &, 584 & & \\
\hline Jamais viajo sem a companhia de um familiar & & & & ,763 & \\
\hline Não gosto de viajar para outros países & & & &,- 678 & \\
\hline Nunca viajo em excursão & & & & & ,847 \\
\hline $\begin{array}{l}\text { Em questões de viagem só ouço a opinião dos } \\
\text { meus familiares }\end{array}$ & & & & & ,595 \\
\hline
\end{tabular}

O componente 1 (organização) inclui a necessidade de viagens organizadas com roteiros préestabelecidos, acompanhamento de guias, escolha livre dos períodos de viagem, companhia de grupos homogêneos, acompanhamento da família, locais com boas condições físicas, ausência de compromissos de trabalho, cuidados especiais com alimentação. O componente 2 (insegurança com coisas) relaciona: comida feita por pessoas estranhas, muito medo de ficar doente em viagens e de acidentes em viagens. O componente 3 (insegurança com pessoas) incluiu não visitar lugares onde não conhece ninguém, inseguro em lugares onde não conhece ninguém e vale a pena correr riscos para viver situações novas. O componente 4 (desconhecimento) relacionou: jamais viajo sem a companhia de um familiar e não gosto de viajar para outros países. Finalmente o último componente (escolha) se refere a: nunca viajo em excursão e em questões de viagem só ouço a opinião dos meus familiares.

\section{Conclusão}


O principal objetivo deste paper foi entender as atitudes em relação ao turismo, manifestadas por indivíduos da terceira idade, residentes na cidade de São Paulo, através da identificação de suas características de consumo do turismo como lazer. A principal limitação está ligada ao tipo de amostragem, não probabilística, cujos resultados alcançados não podem ser generalizados.

Pode-se dizer que os resultados apontam no sentido de que o os hábitos referentes a viagens (destino, número de viagens, motivos, tipos de acompanhantes, época da viagem) e o estado de espírito da população mais idosa pode interferir em suas atitudes relativas a viagens de lazer. Embora não passíveis de generalização, os cinco componentes identificados na análise fatorial estão alinhados com os resultados encontrados na literatura e sintetizam as dimensões latentes no conjunto de atitudes em relação a turismo.

As conclusões também corroboram estudo feito por Diniz e Mota (2006), segundo o qual há barreiras e hierarquias que impactam o consumidor de terceira idade com relação a lazer, relacionados a três fatores (estruturais, interpessoais e intrapessoais) que são: receios, apoio interno e externo, recursos financeiros, tempo, interação social, medo de transporte, companhia, busca de experiências. As barreiras estruturais se apresentam em função do estágio no ciclo de vida, recursos financeiros, estação do ano, clima, horário de trabalho, existência de oportunidade e outras mais que impedem o consumidor de participar da atividade de sua preferência. Barreiras intrapessoais envolvem o estado psicológico dos consumidores e outras características pessoais que interagem com as preferências de lazer mais do que entre a preferência e a participação e as barreiras intrapessoais se manifestam pelo stress, depressão, ansiedade, religiosidade ou outras avaliações subjetivas.

Em outra perspectiva, a revisão da bibliografia mostrou que têm sido pouco exploradas as implicações potenciais quanto a atitudes e grau de importância da congruência entre hábitos, estado de espírito, assim, este trabalho poderia auxiliar especialistas de marketing tanto na segmentação como na relação de compra e uso de produtos e serviços voltados para a terceira idade.

\section{Referências Bibliográficas}

ABAV (Associação Brasileira das Agências de Viagem). 2005. Disponível em: http://www.abav.com.br. Acesso em: ago. 2006.

ACERENZA, M. 2002. Administração do turismo. Bauru: EDUSC. 
ACEVEDO, C. 1998. Perfil do comportamento do consumidor maduro em viagens de lazer. Tese de doutorado, São Paulo: EAESP FGV.

AMARAL, S. 2004. Segmentação de mercado com enfoque em valores e estilo de vida segmentação psicográfica - um estudo exploratório. Universidade de São Paulo.

BACHA, M.L.; STREHLAU, V.I.; PEREZ, G. 2006. A Compreensão do significado do termo terceira idade pela terceira idade em São Paulo. Anais eletrônicos do II EMA, ENANPAD.

BARBOSA, L.; O’NEIL, I.; MARINS, C.,2005 British Travellers' image perspectives of Brazil as a tourism destination. Anais eletrônicos do $29^{\circ}$ ENANPAD.

BARBOSA, L.; ZAMOT, F. 2004. Políticas Públicas Para o Desenvolvimento do Turismo: o Caso do Município de Rio das Ostras. Anais eletrônicos do $28^{\circ} E N A N P A D$.

BARROS, F.; MOREIRA, M. 2005. O Capital Social nas Aglomerações Produtivas de Micro e Pequenas Empresas: Estudo de um Arranjo Produtivo Turístico. Anais eletrônicos do $29^{\circ}$ ENANPAD.

2005. O Comportamento Empreendedor e suas Implicações: a Organização Produtiva de Micro e Pequenas Empresas no Turismo. Anais eletrônicos do $29^{\circ}$ Enanpad.

BENI, M. 1997. Análise Estrutural do Turismo. São Paulo: SENAC.

BERTON, L.; CUNHA, S.; CUNHA, J., 2005. Planejamento e Governança de um Cluster Turístico. Anais eletrônicos do $29^{\circ}$ Enanpad.

BOULLÓN, R.. 2004. Atividades turísticas e recreativas: o homem como protagonista. Bauru, EDUSC.

BURLAMAQUI, P.; SANTOS, A., 2004. Marketing de Experiência na Internet: Um Estudo sobre a Percepção dos Estímulos Sensoriais em Portais Turísticos na WEB Brasileira. Anais eletrônicos do $28^{\circ}$ Enanpad.

CALLAN, R. KYNDT, G. 2001. Business travellers' perception of service quality: a prefatory study of two European city centre hotels, The International Journal of Tourism Research. Chichester: Jul/Aug Vol. 3, Num. 4; p. 313.

CAMPOS, T. 2003. Lazer e terceira idade: contributos do turismo no âmbito do programa clube da melhor idade, dissertação de mestrado. Campinas: UNICAMP.

CASIMIRO FILHO, F. 2003. Contribuição do turismo à economia brasileira. Tese de Doutorado. USP - Unidade Escola Superior de Agricultura Luiz de Queiroz.

COHEN, J. 2002, The contemporary tourist: is everything old new again? Advances in Consumer Research, vol. 22, p.31-35.

CRISPIM, S.; DULTRA, G., 2005. Inserção da Internet no Ambiente Competitivo do Turismo: Uma Pesquisa Aplicada ao Setor Hoteleiro de Ribeirão Preto, SP. Anais eletrônicos do $29^{\circ}$ Enanpad.

CUNHA, S.; CUNHA, J. 2005. Modelo Sistêmico para Avaliação do Impacto do Turismo no no Desenvolvimento Local, anais eletrônicos do $29^{\circ}$ ENANPAD.

DIAS, E., 2000. A Importância da Gestão do Capital Humano na Indústria do Turismo. Anais eletrônicos do $23^{\circ}$ ENANPAD.

DINIZ, F.; MOTTA,P.2006. Em Busca de um Modelo de Restrição ao Lazer para os Consumidores de Mais Idade, anais eletrônicos $30^{\circ}$ ENANPAD.

FALK, C.; REBOUÇAS, G. 2003. Uma Investigação Empírica Acerca dos Condicionantes da Intenção do Turista de Voltar ao Recife: Uma Ferramenta para a Gestão do Turismo Sustentável. Anais eletrônicos do $27^{\circ}$ ENANPAD.

FELICE, A. 2002. Turismo Rural para terceira idade. Dissertação de mestrado. Universidade de São Paulo. 
FERREIRA, S.; CHAUVEL, M., 2004. Gerenciamento Ecológico: do Garimpo ao Empreendedorismo Ambiental e Socialmente Responsável. Anais eletrônicos do $28^{\circ}$ ENANPAD.

FLEISCHER, A.; SEILER, E. 2002 Determinants of vacation travel among Israeli seniors: theory and evidence. Applied Economics, 34, p. 421-430.

FORMICA, S. 2002. Measuring destination attractiveness: A proposed framework. Journal of American Academy of Business, Cambridge. Hollywood: Mar Vol. 1, Num. 2; p. 350.

GARCIA, J. 2001. Como Enfrentar a Velhice. São Paulo: Ícone/Campinas, UNICAMP.

GARCIA, M. 2001. Turismo na terceira idade: um mercado em potencial. Tese de doutorado. Universidade de São Paulo.

GEE, C.; MAKENS, J.; CHOY, D. 1989. The Travel Industry, 2nd edn. New York: Van Nostrand Reinhold.

GIRALDI, J.; CRESCITELLI, E. 2006. Desenvolvimento de Marca-País: uma Abordagem Teórica sobre as Dificuldades e Similaridades com o Desenvolvimento de Marca para Produtos. Anais eletrônicos do II Encontro de Marketing EMA da ANPAD.

GNOTH, J.; ANWAR, S. 2000. New Zealand bets on event tourism. Cornell Hotel and Restaurant Administration Quarterly. Ithaca: Aug Vol. 41, Num. 4; p. 72.

HUANG, L.; TSAI, H. 2003. The Study of Senior Traveller Behaviour in Taiwan, Tourism Management, 24(5): 561-74.

IBGE, Estatísticas populacionais, sociais, políticas e culturais, disponível em http://www.ibge.gov.br/, acessado em agosto de 2006.

IBRAHIM, E.; GILL, J. 2005. A positioning strategy for a tourist destination, based on analysis of customers' perceptions and satisfactions. Marketing Intelligence \& Planning. Bradford: Vol. 23, Num. 2/3; p. 172.

IWASSO, S. 2006. Comum na adolescência, intercâmbio também seduz a terceira idade, Jornal O Estado de S.Paulo, Sexta-feira, 6 janeiro de 2006, VIDA\&, disponível em http://www.estado.com.br/editorias/2006/04/28/.

JAVALGI, R.; THOMAS, E.; RAO, S. 1992. Consumer Behaviour in the US Pleasure Travel Marketplace: An Analysis of Senior and Non-Senior Travellers, Journal of Travel Research, 31(2): 14-19.

KIM, S.; M, S. 1996. The Tourism Constraints of the Ageing Population. Journal of Tourism Sciences, 19(1): 35-51.

KOHLER, A.; DURAND, J. 2003. Patrimônio Histórico-Cultural e Turismo em Pernambuco: Metodologia de Criação de Novos Roteiros Turísticos. Anais eletrônicos do $26^{\circ}$ ENANPAD.

LADEIRA, R.; GUEDES, E.; BRUNI, A. 2003. Um Estudo do Comportamento do Consumidor Soteropolitano de Terceira Idade em Relação ao Entretenimento e ao Lazer com Ênfase no Turismo. Anais eletrônicos do $26^{\circ}$ ENANPAD.

LEE, S.; TIDESWEL, C. 2005. Understanding attitudes towards leisure travel and the constraints faced by senior Koreans. Journal of Vacation Marketing. London: Jul Vol. 11, Num. 3; p. 249, 15 pgs.

LUK, S. 1997. An examination of the role of marketing culture in service quality. International Journal of Contemporary Hospitality Management. Bradford: Vol. 9, Num. 1; p.13.

MAZANEC, J. 1993. 'Exporting' Eurostyles to the USA. International Journal of Contemporary Hospitality Management. Bradford: Vol. 5, Num. 4; p. 3.

MAZARO, R.; VARZIN, G. 2005. Modelos de Competitividade para Destinos Turísticos. Anais eletrônicos do $29^{\circ}$ ENANPAD. 
MCGUIRE, F. 1984. A Factor Analytical Study of Leisure Constraints in Advanced Adulthood, Leisure Sciences, 6(3): 313-26,

MCGUIRE, F.; BOYD, R.; TEDRICK, R. 1996. Leisure and Ageing: Ulyssean Living in Later Life. Champaign: Sagamore Publishing.

MOREIRA, M., 2000. Determinantes demográficos do envelhecimento brasileiro. In: Encontro Nacional De Estudos Populacionais Anais..., 8., Caxambu. Caxambu: ABEP.

MULLER, T.; O'CASS, A. 2001. Targeting the Young at Heart: Seeing Senior Vacationers the Way They See Themselves, Journal of Vacation Marketing, 7(4): 285-301.

NONOHAY, M.; VIEIRA, D.; BOARO, L., 2005. O Valor das Imagens nas Avaliações de Valor Para o Cliente. Anais eletrônicos do $29^{\circ} E N A N P A D$.

OLIVEIRA, B.; CAMPOMAR, M. 2006. O Processo de Posicionamento Competitivo em Marketing. Anais eletrônicos do II Encontro de Marketing EMA da ANPAD.

OLIVEIRA, V.; ROMANIELLO, M. 2005. Considerações Sobre as Mudanças nas Estratégias Brasileiras de Desenvolvimento. Anais eletrônicos do $29^{\circ}$ ENANPAD.

OMT, WTO (World Tourism Organization) Tourism Highlights 1999, Revised Preliminary Estimates, 1999.WTO- World Tourism Organization. Disponível em: http://www.world-tourism.org/, acessado em agosto de 2006.

PEARCE, D. 2001. Tourism and urban land use change: Assessing the impact of Christchurch's tourist tramway, Tourism and Hospitality Research. London: Sep Vol. 3, Num. 2; p.132.

PEREIRA, L. 2004. Valores e Estratégia Organizacional: Estudo Comparativo de Casos em Órgãos Oficiais de Turismo. Anais eletrônicos do $28^{\circ}$ Enanpad.

PETTERSSON, R. 2002. Sami tourism in northern Sweden: Measuring tourists' opinions using stated preference methodology. Tourism and Hospitality Research. London: Apr Vol. 3, Num. 4; p. 357.

REZENDE, C.; REZENDE, D. 2005. Impactos do Turismo: Uma Análise Sob a Ótica da População Receptora. Anais eletrônicos do $29^{\circ}$ Enanpad.

ROCHA, S. 2004. Internet Marketing: Como A Indústria Hoteleira Responde A Solicitações De Informações Via Correio Eletrônico? O Caso Do Município Do Rio De Janeiro. Anais eletrônicos do $28^{\circ}$ Enanpad.

RODRIGUES, J. 2004. Gestão da Satisfação e da Fidelidade de Consumidores: Um Estudo dos Fatores que Afetam a Satisfação e a Fidelidade no Mercado de Turismo. Anais eletrônicos do $28^{\circ}$ Enanpad.

ROSS, G. 1992. Work Attitudes and Management Values: The Hospitality Industry. International Journal Contemporary Hospitality Management. Bradford: Vol. 4, n3; p. 9

SANTOS, G. 2005. Modelo gravitacional do turismo: proposta teórica e estudo empírico dos fluxos turísticos no Brasil. Dissertação de Mestrado. Universidade de São Paulo.

SANTOS, I. 2005. Análise acústica da voz de indivíduos na terceira idade. Tese de doutorado. Escola de Comunicações e Artes. Universidade de São Paulo.

SCHRRINER, E. 2004. Uma especulação sobre a Internet no operador de turismo: o caso CVC. Dissertação de Mestrado em Administração. EAESP-FGV.

SILVA, J. 2005. Turismo, crescimento e desenvolvimento: uma análise urbano-regional baseada em cluster, Tese de doutorado. Universidade de São Paulo.

SILVA, J.; COSTENARO, A. 2004. Planejamento Estratégico: um recurso para o desenvolvimento do turismo municipal. Anais eletrônicos do $28^{\circ}$ Enanpad.

SOUZA, F. 1998. Comportamento psicossocial do turista na terceira idade. Dissertação de mestrado. Escola de Comunicações e Artes.Universidade de São Paulo. 
SOUZA, M.; FERREIRA, E.; SOUZA, C. 2005. O Setor Turístico sob o Enfoque do Desenvolvimento Sustentável: um Estudo na Cidade de Florianópolis/SC. Anais eletrônicos do $29^{\circ}$ Enanpad.

STUART-HAMILTON, I. 2002. Psicologia do Envelhecimento: Uma Introdução, Porto Alegre: Artmed.

TEIXEIRA, H. 2001. A Trajetória dos Pequenos Negócios do Ramo de Turismo na Região de Belo Horizonte e Poços de Caldas (MG) - um estudo sobre o mito ou a realidade do processo de empreendedorismo. Anais eletrônicos do $24^{\circ}$ ENANPAD.

TOLEDO, G.; POLERO, A.; VALDÉS, J. 2002. Estrategias organizacionales del sector de turismo en el ambiente globalizado. Estudio de casos de clusters turísticos. Anais eletrônicos do $26^{\circ}$ Enanpad.

VAZ, G. 1999. Marketing turístico, São Paulo: Pioneira.

WANDERLEY, H. 2004. A percepção dos hóspedes quanto aos atributos oferecidos pelos hotéis voltados para o turismo de negócios na cidade de São Paulo. Dissertação de mestrado. Universidade de São Paulo.

YUAN, J. et al.. 2005. An analysis of wine festival attendees' motivations: A synergy of wine, travel and special events? Journal of Vacation Marketing, London: Jan Vol. 11, Num. 1; p. 41.

ZIMMER, Z.; BRAYLEY, R.; SEARLE, M. 1995. Whether to Go and Where to Go: Identification of Important Influences on Seniors' Decisions to Travel, Journal of Travel Research, 33(3): 3-10.

ZOUAIN, D.; BARBOSA L.; MARTELLOTE, M. 2005. Os Impactos Econômicos do Turismo no Município do Rio de Janeiro e suas Implicações no Desenvolvimento Local. Anais do $29^{\circ}$ Enanpad 2005.

\section{Recebido em: 15/11/2006}

Aprovado em: 09/04/2007 